\title{
Preface
}

This volume contains the proceedings of the 11th International Conference on Relational Methods in Computer Science (RelMiCS 11) and the 6th International Conference on Applications of Kleene Algebra (AKA 6). The joint conference took place in Doha, Quatar, from November 1 to November 5, 2009. Its purpose was to bring together researchers from various subdisciplines of Computer Science, Mathematics and related fields who use the calculus of relations and/or Kleene algebra as methodological and conceptual tools in their work.

This conference is the joint continuation of two different strands of meetings. The seminars of the RelMiCS series were held in Schloss Dagstuhl (Germany) in January 1994, Parati (Brasil) in July 1995, Hammamet (Tunisia) in January 1997, Warsaw (Poland) in September 1998, Québec (Canada) in January 2000, and Oisterwijk (The Netherlands) in October 2001. The conference on Applications of Kleene Algebra started as a workshop, also held in Schloss Dagstuhl, in February 2001. To join these two themes in one conference was mainly motivated by the substantial common interests and overlap of the two communities. Over the years this has led to fruitful interactions and openened new and interesting research directions. Joint meetings have been held in Malente (Germany) in May 3003, in St Catherines (Canada) in February 2005, in Manchester (UK) in August/September 2006 and in Frauenwörth (Germany) in April 2008.

This volume contains 24 contributions by researchers from all over the world. Next to 22 regular papers there were the invited talks Computational Social Choice using Relation Algebra and RELVIEw by Harrie de Swart (Tilburg University, Netherlands) and Knowledge and Structure in Social Algorithms by Rohit Parikh (Brooklyn College and CUNY Grad Center, USA). The papers show that relational and Kleene Algebra methods have wide-ranging diversity and applicability in theory and practice.

In addition, for the third time, a $\mathrm{PhD}$ programme was offered. It included the invited tutorials $X X$ by Marcelo Frías (University of Buenos Aires, Argentina), $X X$ by Ali Jaoua (University of Qatar at Doha) and Relational Methods at Work by Gunther Schmidt (University of the Armed Forces at Munich, Germany).

We are very grateful to the members of the Programme Committee and the external referees for their care and diligence in reviewing the submitted papers. We also want to thank Qatar University for having accepted to host the conference and Aws Al-Taie, Fatma Al-Baker, Zeina Hazem Al-Azmeh, Fatma Al-Bloushi and Mohamad Hussein for their assistance; they made organizing this meeting a pleasant experience. We also gratefully appreciate the excellent facilities offered by the EasyChair conference administration system. Finally, we cordially thank our sponsors Supreme Education Council (SEC), Qatar National Research Fund (QNRF) and Qatar University (QU) for their generous support.

November 2009

Rudolf Berghammer Ali Jaoua

Bernhard Möller 


\section{Programme Committee}
J Al'Jaam
R. Berghammer
H. de Swart
J. Desharnais
R. Duwairi
M. Frías
H. Furusawa
P. Hoefner
A. Jaoua
P. Jipsen
W. Kahl
Y. Kawahara
L. Meinicke
A. Mili
B. Möller
C. Morgan
E. Orłowska
S. Saminger-Platz
G. Schmidt
R. Schmidt
G. Struth
M. Winter

\section{External Referees}

\author{
Bernd Braßel \\ Jean-Lou De Carufel \\ Jan Christiansen \\ Ernst-Erich Doberkat \\ Han-Hing Dang \\ Ernst-Erich Doberkat \\ Roland Glück
}

Doha, Qatar

Kiel, Germany

Tilburg, Netherlands

Laval, Canada

Doha, Qatar

Buenos Aires, Argentina

Kagoshima, Japan

Augsburg, Germany

Doha, Qatar

Chapman, USA

McMaster, Canada

Kyushu, Japan

Sydney, Australia

Tunis, Tunisia; New York, USA

Augsburg, Germany

Sydney, Australia

Warsaw, Poland

Linz, Austria

Munich, Germany

Manchester, UK

Sheffield, UK

Brock, Canada

Koki Nishizawa

Viorel Preoteasa

Ingrid Rewitzky

Pawel Sobocinski

Kim Solin

Sam Staton 